\title{
Assessing Care Nursing Measure for Patients of Induced Abortion
}

\author{
Jiaona Tang, Xinke Huang*, Hong Zhou, Xiaojuan Liao \\ Gynecology Department, The First Affiliated Hospital of Jinan University, Guangzhou, China \\ Email address: \\ 807876002@qq.com (Jiaona Tang),929901838@qq.com (Xinke Huang), 1969034653@qq.com (Hong Zhou), \\ L8808104@126.com (Xiaojuan Liao) \\ ${ }^{*}$ Corresponding author
}

\section{To cite this article:}

Jiaona Tang, Xinke Huang, Hong Zhou, Xiaojuan Liao. Assessing Care Nursing Measure for Patients of Induced Abortion. Journal of Gynecology and Obstetrics. Vol. 8, No. 1, 2020, pp. 32-34. doi: 10.11648/j.jgo.20200801.18

Received: February 14, 2020; Accepted: February 24, 2020; Published: March 3, 2020

\begin{abstract}
Objective: to evaluate influence of care nursing measure on induced abortion patients. Methods: we screened 100 suitable patients to join our study, who were undergoing induced abortion, their information was collected from March 2016 to October 2019. The patients who their age was between 20 and 45 years were randomly assigned to intervention group and a control group. For the two groups, we use the different nursing measure for the patients of different group. In nursing process, we collected their data of anxiety and depression by Self-Rating Anxiety Scale (SAS) and Self-rating depression scale (SDS). In addition, we use interview to collect the status of contraception awareness and contraceptive use. Result: the patients of intervention group had better mental health than patients of control group, that the intervention group had bigger change $(48.75 \pm 9.17$ vs $40.13 \pm 7.87,49.82 \pm 9.62$ vs $38.74 \pm 7.14)$. For contraception awareness, the result of intervention group is obviously better than that of control group $(94.23 \pm 3.68$ vs $81.93 \pm 5.13)$. The patients still had repeated abortion during follow-up, but patients of intervention group had less repeated abortion status than the control group [5 (10\%) vs $1(2 \%)]$. However, the intervention group had higher contraceptive use rate from our research [28 (56\%) vs 46 (92\%)]. Conclusion: the care nursing measure had better influence in mental health of induced abortion patient and wonderful effect at precaution consciousness of repeated induced abortion.
\end{abstract}

Keywords: Nursing, Induced Abortion, Repeated Abortion

\section{Introduction}

Most adolescent or teenage pregnancies, which occur from menarche and before 20 years of age, are unwanted as a result of ineffective contraception and often result in induced abortion over concerns regarding starting a family too early and the possible negative effect on personal career plans $[1,2]$ A recent systematic review and meta-analysis of 38 studies estimated that the average induced abortion rate worldwide is approximately 58 per 1000 women [3]. In Europe, there is an estimated prevalence of teenage induced abortions (TIAs) of $12.2 \%$ [4]. Moreover, in the United States the reported rate was $29.2 \%$, whereas in Russia it was as high as $56.1 \%$, the published data have shown that countries from northern Europe report the highest rates of induced abortions (United Kingdom and Sweden reported rates of $22.5 \%$ ), whereas the lowest rates have been reported from southern and western
Europe (in Malta abortions are prohibited so the reported rates are $0.0 \%)[5,6]$.

From 2012 to 2014, More than 26 million induced abortions were carried out among women aged 15-44 worldwide [7, 8]. The induced abortion make many women had bad mental health status. For example, a 2014 study including 3310 women aged 18 years and over showed that, after adjusting for sociodemographic variables, abortion was positively associated with mood disorders, anxiety disorders, substance use disorders, suicidal ideation, and suicide attempts [9, 10]. However, a 2014 cohort study of 936 participants found no significant association between abortion and mental disorders after adjusting for confounding factors [11, 12]. The aim of our study was assess the care nursing measure for the patients who undergoing induced abortion.

\section{Methods}




\subsection{Participants Enrollment}

We invited the patients to join our study when they were diagnosed as require to undergoing induced abortion. Their diagnosis of time were between March 2016 and October 2019. In the participants $(n=100)$, they were randomly assigned to two groups which were intervention group $(n=50)$ and a control group $(\mathrm{n}=50)$. They were asked to complete Self-Rating Anxiety Scale (SAS) and Self-rating depression scale (SDS) [13-15], the questionnaires are focus on assess anxiety and depression of participants in duration of hospital stay. In addition, our researchers record contraceptive awareness and contraceptive measures status by interview and telephone follow-up. We recorded repeated abortion rate and contraceptive use rate in 1 year after induced abortion.

Their inclusion criteria were: (1) the patients undergoing induced abortion; (2) Gestation weeks 5-12 weeks; (3) no mental illness or disturbance of consciousness; (4) their age were between 20 and 45 years old. Their withdraw criteria were: (1) the patients had acute genital inflammation; (2) the patients had serious physical and mental illness. All participants voluntarily participated in this study and signed informed consent.

\subsection{Statistical Analysis}

Our data analyzer performed the statistical analysis by SPSS 22.0. The $\mathrm{P}$ value, t-test and chi-square test were associated with collection result were analyzed. Besides, the mean standard deviation for statistical description.

\section{Result}

The result of SAS and SDS present anxiety and depression of patients (Table 1). In the result, the patients of intervention group had better mental health than patients of control group, that the intervention group had bigger change (48.75 \pm 9.17 vs $40.13 \pm 7.87,49.82 \pm 9.62$ vs $38.74 \pm 7.14$ ). Additionally, the improvement result had statistical significance $(\mathrm{p}<0.005)$.

Table 1. The Result of SAS and SDS.

\begin{tabular}{lllll}
\hline \multirow{2}{*}{ Projects } & SAS & & SDS \\
\cline { 2 - 4 } & BN & FN & BN & FN \\
\hline Control Group $(\mathrm{n}=50)$ & $55.34 \pm 10.68$ & $48.75 \pm 9.17$ & $53.68 \pm 9.56$ \\
Intervention Group $(\mathrm{n}=50)$ & $54.97 \pm 10.51$ & $40.13 \pm 7.87$ & $53.35 \pm 9.17$ & 0.1762 \\
$\mathrm{~T}$ & 0.1746 & 5.044 & 0.141 & $6.82 \pm 9.62$ \\
P value & 0.041 & $<0.005$ & $<.74 \pm 7.14$ & $<0.005$ \\
\hline
\end{tabular}

SAS=Self-Rating Anxiety Scale.

SDS=Self-rating depression scale.

$\mathrm{BN}=$ before the nursing.

$\mathrm{FN}=$ after the nursing.

The data of the status of contraception awareness and contraceptive use was collected from interview in post-discharge. It shown contraception awareness of patient and their contraceptive use status had slightly improvement (Table 2). For contraception awareness, the result of intervention group is obviously better than that of control group $(94.23 \pm 3.68$ vs $81.93 \pm 5.13)$. The result had statistical significance $(p<0.005)$. Besides, contraceptive use status had improvement in all patient, the data of two groups had not significant gap.

Table 2. The Status of Contraception Awareness and Contraceptive Use after Care Nursing [Mean $\pm S D, n(\%)]$.

\begin{tabular}{|c|c|c|c|c|c|c|}
\hline \multirow{2}{*}{ Projects } & \multicolumn{2}{|c|}{ Contraception awareness } & \multicolumn{4}{|l|}{ Contraceptive Use } \\
\hline & BN & FN & Intrauterine device & Oral contraceptive & Condoms & Emergency contraception \\
\hline Control Group $(\mathrm{n}=50)$ & $62.85 \pm 9.57$ & $81.93 \pm 5.13$ & $7(14.0)$ & $3(6.0)$ & $15(30.0)$ & $3(6.0)$ \\
\hline Intervention Group $(n=50)$ & $64.31 \pm 9.89$ & $94.23 \pm 3.68$ & $15(30.0)$ & $6(12.0)$ & $25(50.0)$ & $0(0.0)$ \\
\hline Statistics & 0.7502 & 13.78 & 2.855 & 0.4884 & 0.5046 & 1.131 \\
\hline P Value & 0.045 & $<0.005$ & 0.091 & 0.048 & 0.031 & $<0.005$ \\
\hline
\end{tabular}

$\mathrm{BN}=$ before the nursing.

$\mathrm{FN}=$ after the nursing.

We assessed the result of repeated abortion rates and contraceptive use rate after collection action (Table 3). The patients still had repeated abortion during follow-up, but patients of intervention group had less repeated abortion status than the control group [5 (10\%) vs $1(2 \%)$ ]. In data of contraceptive use rate, the intervention group had higher contraceptive use rate from our research [28 (56\%) vs 46 $(92 \%)]$.

Table 3. Repeated Abortion Rates and Contraceptive Use Rate [n (\%)].

\begin{tabular}{llll}
\hline Projects & Repeated Abortion Rates & Contraceptive Use Rate & X $^{2}$ \\
\hline Control Group $(\mathrm{n}=50)$ & $5(10.0)$ & $28(56.0)$ & 7.696 \\
Intervention Group $(\mathrm{n}=50)$ & $1(2.0)$ & $46(92.0)$ & 0.006 \\
$X^{2}$ & 4.414 & 15.02 & - \\
P Value & 0.035 & $<0.005$ & - \\
\hline
\end{tabular}




\section{Discussion}

A part of women undergoing one abortion have experienced more previous procedures. $38 \%$ of abortions performed in England and Wales were among women with histories of one or more abortions in 2017 [16]. As the report, the rate of repeated induced abortion of United States woman was $43.0 \%$ in 2016 [8]. In addition, most adolescent or teenage pregnancies, which occur from menarche and before 20 years of age, are unwanted as a result of ineffective contraception and often result in induced abortion over concerns regarding starting a family too early and the possible negative effect on personal career plans. In a recent study conducted in Greece, more than $40 \%$ of women hospitalized due to pregnancy complications reported their pregnancy as unplanned [17]. The high prevalence of repeated induced abortion in China is also of public health concern.

Following to the result, the care nursing measure had better effect than the traditional nursing measure for the induced abortion. It not only provide better mental health to patients who undergoing induced abortion but also reduce the rate of repeated induced abortion in post-discharge. For one things, the patients of intervention group had less anxiety and depression in duration of hospital stay. But the improvement result had not big gap between the intervention group and control group. For other things, the patients of intervention group had better precaution consciousness to avoid repeated induced abortion, they had better contraception awareness and higher contraceptive use rate in post-discharge.

\section{Conclusion}

In conclusion, the care nursing measure had better influence in mental health of induced abortion patient and wonderful effect at precaution consciousness of repeated induced abortion. However, the changing of mental health had not big gap between the intervention group and control group. In limits, we lack enough number of participants for our simple size, so our result of this study was no statistical significance in some parts, such as contraceptive use status and SDS result In the suggest, the hospital provide care nursing measure in a part of induced abortion patients, who need to pay expensive medical costs. Because the care nursing measure also need spend expensive medical costs in treatment process as the patients who can pay expensive medical fee like to the fee of the care nursing measure.

\section{References}

[1] Fagley R: The Population Explosion and Christian Responsibility. New York, Oxford University Press. 2016: 164-166.

[2] Direkvand-Moghadam, Ashraf, Sayehmiri K, Delpisheh A, Direkvand-Moghadam A. The global trend of infertility: an original review and meta-analysis. Int. J. Epidemiol. Res. 2014; 1: 35-43.

[3] Dastgiri S, Yoosefian M, Garjani M, Kalankesh LR. Induced abortion: a systematic review and meta-analysis. Mater. Socio-Medica. 2017; 29: 58-67.

[4] Part K, Moreau C, Donati S, et al: Teenage pregnancies in the European Union in the context of legislation and youth sexual and reproductive health services. Acta Obstet Gynecol Scand. 2016; 92: 1395 .

[5] Singh S, Darroch JE: Adolescent pregnancy and childbearing: levels and trends in developed countries. Fam Plann Perspect. 2017; 32: 14 .

[6] Graham ML, Hill E, Shelley JM, Taket AR. An examination of the health and wellbeing of childless women: a cross-sectional exploratory study in American. BMC Womens Health. 2011; 11: 47.

[7] Sedgh G, Bearak J, Singh S, Bankole A, Popinchalk A, Ganatra B, et al. Abortion incidence between 1990 and 2014: global, regional, and subregional levels and trends. Lancet 2016; 388 (10041): 258-67.

[8] Jatlaoui TC, Ewing A, Mandel MG, Simmons KB, Suchdev DB, Jamieson DJ, et al. Abortion surveillance - United States, 2013. MMWR Surveill Summ 2016; 65 (12): 1-44.

[9] Mota NP, Burnett M, Sareen J. Associations between abortion, mental disorders, and suicidal behaviour in a nationally representative sample. Can. J. Psychiatry Rev. Can. Psychiatr. 2015; 55: 239-247.

[10] Lamina MA. Prevalence of abortion and contraceptive practice among women seeking repeat induced abortion in Western Nigeria. J Pregnancy. 2015; 15: 486203.

[11] Steinberg JR. McCulloch CE. Adler NE. Abortion and mental health: findings from the National Comorbidity Survey-Replication. Obstet. Gynecol. 2014; 123: 263-270.

[12] Magnusson BM, Masho SW, Lapane KL. Early age at first intercourse and subsequent gaps in contraceptive use. J Womens Health (Larchmt) 2015; 21 (1): 73-9.

[13] White D, Leach C, Sims R, Atkinson M, Cottrell D. Validation of the Hospital Anxiety and Depression Scale for use with adolescents. Br J Psychiatry 1999; 175: 452-454.

[14] El-Rufaie O, Absood G. Validity study of the Hospital Anxiety and Depression Scale among a group of Saudi patients. Br J Psychiatry 1987; 151: 687-688.

[15] McPherson R., Frohlich J., Fodor G., Genest J., Canadian cardiovascular society position statement e recommendations for the diagnosis and treatment of dyslipidemia and prevention of cardiovascular disease, Can. J. Cardiol. 2006; (22): 913-927.

[16] Department of Health of UK. Abortion Statistics, England and Wales; 2017.

[17] Dagklis T, Tsakiridis I, Chouliara F, et al: Antenatal depression among women hospitalized due to threatened preterm labor in a high-risk pregnancy unit in Greece. J Matern Fetal Neonatal Med 2018; 31: 919. 